\title{
A Crítica como Ferramenta de Liberdade ${ }^{\mathrm{i}}$
}

Arlindo Rodrigues Picoli ${ }^{\text {ii }}$

\section{Resumo}

Este ensaio problematiza as relações entre a crítica e a liberdade conforme Michel Foucault. Apresenta o resultado de uma investigação especulativa baseada no estudo e em experiências interpretativas dos textos. A necessidade de desenvolver nos estudantes a capacidade crítica, é uma constante em muitos discursos pedagógicos da atualidade. A utilização da crítica como ferramenta de liberdade nos incentiva a criar novas práticas na escola.

\section{Introdução}

A concepção iluminista eminentemente subjetiva de emancipação exigiu a articulação de velhas palavras com sentido renovado que ajudaram a deslocar a libertação, que antes era exercida por uma exterioridade, como no caso do Estado, para o interior dos indivíduos. Uma delas, lapidada por Kant e que ecoa até hoje no discurso pedagógico da atualidade é a crítica. Na educação brasileira contemporânea tal palavra ganhou uma grande importância, mas seu sentido se perdeu no vazio dos discursos.

A crítica ${ }^{\text {iii }}$ em geral indica a nossa capacidade de julgar, decidir, discernir e mesmo de pensar. No iluminismo, foi dirigida para o sujeito racional, uma vez que era realizado o julgamento de certezas, da fé e mesmo daqueles saberes sustentados por argumentos de autoridade e defendidos energicamente pelas religiões ou instituições políticas. A crítica kantiana indicava os meios pelos quais a razão conhece a si mesma, refutando toda aspiração sem fundamentos, reconhecendo seus limites, questionando seus princípios e pretensões ao conhecimento e evitando todas as formas de engano.

Entretanto, longe de ser neutro, este julgamento aparentemente imparcial, pode estar comprometido com uma posição já estabelecida. Na História da Loucura (1961) Foucault nos apresenta a 'consciência crítica' que finge ser rigorosa e fazer a crítica radical de si mesma. Aplicada a loucura, a consciência crítica procura desde já, reconhecê-la e denunciá-la amparada pela razão e pela moral. Dessa maneira, a loucura é concebida, com o consentimento da crítica, a partir de uma oposição ressentida (FOUCAULT, 2008b, p. 3). Longe de esclarecer, ou de revelar, o discernimento nestes termos oculta a experiência trágica e cósmica da loucura, disfarçada por uma consciência sempre ávida de vantagens e que se diz crítica, filosófica ou científica (FOUCAULT, 2008a, p. 26).

No texto de 1971, Monstruosidade da crítica, respondendo a alguns ataques “críticos” 
de sua obra, ele nos mostra a possibilidade de embuste no ambiente crítico e que, no entanto, se apresenta de forma surpreendentemente lógica (FOUCAULT, 2006b, p. 317). Acreditamos que os quatro métodos clássicos de transformação que Foucault atribui a um texto dissimulado de crítico, também são válidos para a pseudocrítica verbalizada ou pensada. Entendemos estas ações ardilosas como: falsificar - fraudar, obter uma aparência enganadora, atribuir-se um status de verdade -, descontextualizar - recortar, citar desconsiderando o que precede ou se segue, desprezando o encadeamento do discurso -, interpolar - introduzir ou intercalar palavras ou frases - e finalmente omitir palavras, frases ou sentidos.

Além de denunciar sua adulteração, Foucault restitui a crítica aos temas e lugares esquecidos ou ocultos por uma razão tendenciosa, assim não é suficiente denunciar racionalmente as instituições, é imprescindível convocar as formas de racionalidade a um tribunal inquiridor. Desta forma, a liberação não seria resultante de uma luta contra os efeitos, mas ao que sustenta e alimenta a racionalidade política (FOUCAULT, 2003, p. 385).

\section{Crítica e genealogia}

Em A ordem do discurso, texto de sua aula inaugural no Collège de France, publicada em 1970, Foucault anuncia a distinção de dois conjuntos de análises em suas próximas investigações, e que são inseparáveis, complementares, alternantes e apoiadas reciprocamente. O conjunto crítico opera de forma negativa, é o que ativa o princípio de inversão, para cercar as formas de exclusão, limitação e apropriação, mostrando a maneira pela qual se formam, modificam e se deslocam; quais forças exercem e em que medida elas são controladas. Aqui, Foucault nos alerta: as interdições não estão sempre no lugar em que pensamos. A crítica investiga a limitação dos discursos por meio do autor, da disciplina, do comentário, dos processos de rarefação, ordenamento, exclusão, reagrupamento e unificação dos discursos. Já o conjunto genealógico apreende o discurso em sua positividade, como poder de instituir domínios de objetos, cuida da formação discursiva nos sistemas de coerção, seja no interior ou exterior dos limites de controle. É o princípio no qual se questiona qual a norma de cada série de discurso, as condições de surgimento, desenvolvimento e mudança, e estuda os limites que afetam a realidade, tratando da formação dos discursos ao mesmo tempo dispersa, descontínua e regular (FOUCAULT, 2006a, p. 65).

Em Nietzsche, a genealogia e a história, texto de 1971, Foucault reafirma a negatividade de seu conceito de genealogia e mostra o quanto ela é complexa e devedora de Nietzsche. Como origem (Ursprung) a genealogia não é metafísica, a origem não está na essência, mas nas lacunas, nas descontinuidades, na discórdia, no disparate, no acidente. Não 
há solenidade na origem, toda origem é baixa e a verdade é apenas um erro que não pode ser refutado. Como providência (Herkunft) é a marca dos acontecimentos e hábitos ancestrais deixados no corpo. O corpo expressa as lutas; nele surgem desejos, insuficiências e erros articulados com a história. Como emergência (Entertehung), é o não-lugar dos combates em que as forças expõem por meio de regras, seu jogo de dominação imposto aos dominados e que justificam a violência. $O$ devir da humanidade, longe de ser uma significação oculta na origem das coisas, como quer a metafísica, é uma interpretação de regras que foram subvertidas e usadas ao contrário e a genealogia é a história dessas interpretações. No curso Genealogia e Poder proferido em 1976 no Collège de France, a genealogia é o “acoplamento do conhecimento com as memórias locais, que permite a constituição de um saber histórico das lutas e a utilização desse saber nas táticas atuais” (FOUCAULT, 2005b, p. 171). Consiste em libertar os saberes singulares, locais, fragmentários e desqualificados; e confrontá-los contra o resultado de poder centralizador do discurso instituído, legítimo, unitário, científico e verdadeiro. Nesse sentido, quando se trata dos procedimentos de uma batalha, ou seja, ações táticas, direcionadas à ciência, podemos dizer que a genealogia é anticientífica.

\section{Muito além dos limites}

No texto O que é a Crítica? Critica e Aufklärung, conferência proferida em 1978, Foucault define a crítica como uma atitude característica da modernidade, forma de pensar, falar e fazer; relação com a existência, com o saber e o agir próprios; relação com a sociedade, a cultura e os outros. Além disso, a crítica é uma ferramenta usada sobre algo diferente dela e relacionada com a verdade, o saber e o poder. Assim, ela é um instrumento da filosofia, ciência, moral, direito, literatura, etc. em geral, concebida como uma virtude. Por volta do século XVI, ocorreu uma expansão da governamentalização, da arte de governar, já praticada antes pela igreja, espalhando-a por outras instituições: educação, política, economia, etc. Reagindo a isso, surgiu na Europa certo tipo de cultura geral, atitude moral e política, maneira de pensar: a arte de não ser governado de determinada maneira, ou seja, a crítica. A respeito disso, Foucault sugere alguns pontos para serem pensados. O primeiro deles diz respeito à Bíblia: a crítica era dirigida à autoridade da Igreja, procurando negar, recusar e limitar o poder eclesiástico, questionando a autenticidade e a verdade da Escritura Sagrada, neste caso a crítica é historicamente bíblica. Uma das maneiras iniciais de resistência ao poder pastoral foi a mística. A gestação da atitude crítica ocidental ocorreu por meio da incorporação da experiência particular mística e da ação institucional e política nas lutas religiosas medievais. Os movimentos espirituais eram o sustentáculo dos confrontos populares, econômicos, e de 
classe, se preferirmos o vocabulário marxista. O segundo ponto é o direito, e podemos pensar que não querer ser governado daquela forma, é uma contestação da legitimidade das leis. Logo, a crítica trata de direitos imprescritíveis: os direitos naturais, portanto é fundamentalmente jurídica. O terceiro ponto é a verdade, a crítica exige razões para aceitar algo, questiona o que a autoridade diz ser verdadeiro. Relacionada ao poder, à verdade, ao sujeito, deste jogo entre a governamentalização e a crítica surgiram as ciências filológicas, a reflexão, a análise jurídica e a reflexão metodológica. Arte, prática ou técnica negadora da vontade servil própria, reflexão que impede o pacifismo dócil, a crítica possibilita o desassujeitamento do sujeito que recusa a se submeter à verdade.

[...] a crítica é o movimento por meio do qual o sujeito se dá o direito de interrogar a verdade sobre seus efeitos de poder e ao poder sobre seus discursos de verdade. Em outras palavras, a crítica será a arte da não servidão voluntária, aquela da indocilidade reflexiva. A crítica teria essencialmente por função o desassujeitamento no jogo do que se poderia chamar, em uma palavra, a 'política da verdade' (FOUCAULT, 1995, p. 10) (tradução nossa). ${ }^{\text {iv }}$

Foucault identifica o iluminismo, a Aufklärung de Kant, com a crítica, mas considera que a coragem de saber aí invocada é o reconhecimento dos limites ${ }^{\mathrm{V}}$ do conhecimento e que a autonomia kantiana não é exatamente uma insubordinação.

Em O que são as luzes?, ensaio de 1984, Foucault deixa claro que embora efetuando incursões sobre o passado, a investigação crítica é dirigida ao presente, seu interesse é analisar os fenômenos históricos que ainda influenciam nossa maneira de ser no atual. Para entendermos nossa realidade precisamos estudar os acontecimentos que reproduzimos, observando também as alterações na contemporaneidade, a partir de si mesmos. Assim, a crítica é o que liga o presente à sua repetição e diversidade. A definição de Kant sobre a Aufklärung "busca uma diferença: qual diferença que ele introduz hoje em relação a ontem?” (FOUCAULT, 2005a, p. 337). Este julgamento do presente é o êthos filosófico, uma atitude moderna, que se define como uma ontologia crítica de si mesmo, um questionar constante do que nos faz ser como somos, de nosso ser histórico, um desafio dos limites que podemos ultrapassar de maneira prática e uma construção subjetiva de nós mesmos, como criaturas livres.

O que eu gostaria de dizer, a propósito dessa função do diagnóstico sobre o que é a atualidade, é que ela não consiste simplesmente em 
caracterizar o que somos, mas, seguindo as linhas de vulnerabilidade da atualidade, em conseguir apreender por onde e como isso que existe hoje poderia não ser mais o que é. E é nesse sentido que a descrição deve sempre ser feita de acordo com essa espécie de fratura virtual, que abre um espaço de liberdade, entendido como espaço de liberdade concreta, ou seja, de transformação possível (FOUCAULT, 2005a, p. 325).

Longe de ser uma rejeição a tudo que chega, o êthos, escapa à redução simplista entre o exterior e o interior e situa-se em suas fronteiras. Os focos desde julgamento não são mais as estruturas formais e universais, a crítica não é transcendental, mas arqueológica e genealógica. Arqueológica porque trata os discursos que interagem com o que pensamos, falamos e fazemos como acontecimentos históricos. Genealógica porque, por meio da compreensão dos dispositivos triplos que nos fazem ser o que somos - verdade, poder e ética-, possibilita:

[...] uma ontologia histórica de nós-mesmos em nossas relações com a verdade, que permite nos construirmos como sujeitos de conhecimento; nas nossas relações com um campo de poder que permite nos constituirmos como sujeitos que agem sobre os outros; e em nossas relações com a moral, que permite nos constituirmos como agentes éticos (REVEL, 2005, p. 53).

Esta crítica é uma “análise dos limites e reflexão sobre eles” (FOUCAULT, 2005a, p. 347), em vez de sugerir um dualismo entre o exterior e o interior, situa-nos na sua dobra. ${ }^{\mathrm{vi}}$ Esta atitude histórico-crítica não permanece apenas no discurso, mas exige a experimentação capaz de colocá-la à prova, efetuando mudanças parciais, testando as mudanças possíveis, exercendo sua liberdade própria e fugindo dos modelos radicais e globais.

Apesar de Foucault atribuir a Kant a ontologia inquiridora da significação da atualidade, ato inaugural de uma preocupação com o presente, ele se afasta e muito da críticametafísica kantiana, que visava a investigação das formas ou leis essenciais da razão pura, o embasamento das coisas supra-sensíveis (cosmologia, Deus ou a alma humana), ou o estudo dos conhecimentos que independem da experiência - a priori, suas fontes, extensão e limites. Para Foucault a impossibilidade do acesso completo ao conhecimento dos próprios limites, em vez de nos paralisar, é um fator de motivação e retomada: “a experiência teórica e prática 
que fazemos de nossos limites e de sua ultrapassagem possível é sempre limitada, determinada e, portanto, a ser recomeçada” (FOUCAULT, 2005a, p. 349).

\section{A arte de não ser governado}

Foucault atribui quatro características à crítica: a aposta, a homogeneidade, a generalidade e a sistematização.

Aposta: consiste em desvincular o crescimento das capacidades - liberdade intersubjetiva, domínios técnicos, produção econômica, instituições sociais, técnicas de comunicação - do crescimento das relações de poder - disciplinas coletivas e individuais, normalização estatal, exigências da sociedade e da população. Trata-se de como impedir que as capacidades sejam vetores que amplificam as relações de poder.

Homogeneidade: é a investigação dos conjuntos de práticas e estratégias dessas práticas. Logo, a referência é o agir humano e sua maneira de atuar, a tecnologia, ou seja, racionalidade organizadora da prática, e a liberdade com a qual reagimos ao que os demais fazem, transformando as regras do jogo. A homogeneidade não se refere às representações auto-impostas, e às condições determinantes desconhecidas de si mesmo.

Sistematização: os conjuntos práticos advêm de três tipos de relações interligadas, concernentes às coisas, aos outros e a si mesmo; correspondendo respectivamente aos eixos do saber, do poder e da ética. Por conseguinte, o questionamento crítico diz respeito à forma como nos construímos como sujeitos de nosso saber, que praticamos ou padecemos nas relações de poder, que nos constituímos eticamente.

Generalidade: apesar do aspecto particular da crítica foucauldiana, à medida em que se destina a um material, época, conjunto de práticas e a discursos, ela tem sua generalidade, entendida como um caráter circular que torna a ressurgir de forma recorrente, como acontece com os temas da razão e da loucura, doença e saúde, crime e lei, etc. A proposta de Foucault é usar esse conceito de generalidade para entender em que medida o que nós estabelecemos como o "saber", o exercício das relações de poder e a experiência que fazemos conosco, não passam de configurações históricas construídas por certo tipo de problematização; e não simplesmente para justificar um acompanhamento desses problemas na história ou mesmo de suas variações. Há que se considerar "o estudo (dos modos) de problematizações (ou seja, do que não é constante antropológica nem variação cronológica) é, portanto, a maneira de analisar, em sua forma historicamente singular, as questões de alcance geral” (FOUCAULT, 2005a, p. 350-351).

Foucault usa a crítica de maneira completamente diferente do que era feito até então. 
Não se trata mais de procurar o sentido oculto, verdadeiro que está por trás das obras, mas de provocar relações inéditas a partir delas, mesmo que em momento algum isso tenha sido o projeto de seu autor.

A crítica contemporânea - e é isso que a distingue do que era feito até muito recentemente - está começando a formular, sobre os diversos textos que ela estuda, seus textos-objetos, uma espécie de combinatória nova. Em vez de reconstituir seu segredo imanente, ela apreende o texto como um conjunto de elementos (palavras, metáforas, formas literárias, conjunto de narrativas) entre as quais é possível fazer surgir relações absolutamente novas, na medida em que eles não foram determinados pelo projeto do escritor, mas apenas tornados possíveis pela própria obra como tal (FOUCAULT, 2005a, p. 69).

Portanto Foucault atribuiu à crítica uma intenção extremamente produtiva para nossa época, direcionando a capacidade de julgamento para o poder, o saber e a ética, encarando-a como uma prática, técnica ${ }^{\text {vii }}$ ou arte de liberdade. Ao considerar a sujeição efetuada nos indivíduos pelos poderes governamentais produtores de verdades, a crítica é o momento de interrogação destas certezas:

Diante e como contrapartida das artes de governar, ou antes como parceira e adversária, quanto da maneira de suspeitar delas, de recusálas, de limitá-las, de lhes encontrar uma justa medida, de transformálas, de procurar escapar dessas formas de governar ou, em todo caso, deslocá-las, a título de reticência essencial, mas também e por isso mesmo como linha de desenvolvimento das artes de governar, teria havido alguma coisa nascida na Europa nesse mesmo momento, uma espécie de forma cultural geral, ao mesmo tempo atitude moral e política, maneira de pensar etc. e que eu chamaria simplesmente arte de não ser governado ou ainda arte de não ser governado assim e a esse preço. E eu proporia então, como uma primeira definição da crítica, esta caracterização geral: a arte de não ser governado de tal forma (FOUCAULT, 1995, p. 9) (tradução nossa). ${ }^{\text {viii }}$

Para problematizar a emancipação em Foucault, é preciso lembrar que ele distingue 
liberação de 'prática de liberdade’, e prefere trabalhar com estes últimos termos. Isto porque Foucault evita se remeter à idéia que irrompe sempre que se fala de emancipação, de uma natureza essencial humana que foi aprisionada por algum poder, e que após um certo processo de lutas, se livraria destes mecanismos repressivos e voltaria a ter uma vida mais feliz e livre. Em vez disso, ele prefere encarar o problema da liberdade como práticas que dizem respeito às relações entre a ação e o pensamento, pois em Foucault, não devemos procurar o pensamento apenas em...

“[...] formulações teóricas, como aquelas da filosofia ou da ciência, ele pode e deve ser analisada em todas as maneiras de dizer, de fazer, de se conduzir onde o individuo se manifesta e age como sujeito de conhecimento, como sujeito ético ou jurídico, como sujeito consciente de si e dos outros. Nesse sentido, o pensamento é considerado como a forma mesma da ação, como a ação tanto que ela implica o jogo do verdadeiro e do falso, a aceitação ou a recusa da regra, a relação a si mesmo e aos outros. O estudo das formas de experiência poderá por conseguinte fazer-se a partir de uma análise “das práticas” discursivas ou não, se designa-se pelos diferentes sistemas de ação enquanto que são habitados pelo pensamento assim entendido ${ }^{\text {ix }}$ (FOUCAULT, 1994, p. 580) (tradução nossa).

As práticas em Foucault são uma regularidade ou racionalidade que organiza o que os homens fazem, tem um caráter sistemático estabelecido pelo saber, poder e pela ética, são recorrentes e constituem uma experiência ou um pensamento.

Nesta perspectiva, o ato livre não seria o resultado de leis, nem estaria no campo jurídico, mas onde o poder e a liberdade se encontram. Assim como o poder, a liberdade seria algo que exercemos, experimentamos e praticamos em cada pequeno ato, durante toda nossa vida. Não podemos mais pensar a liberdade apenas como o efeito de algo exterior ao sujeito, ou alguma meta só realizável coletivamente num futuro distante, ou como algo abstrato. Por isso, se quisermos pensar a emancipação em Foucault, precisamos desdobrá-la, separá-la das utopias, dos sentidos que lhe foram atribuídos de acordo com certos momentos históricos, e também das concepções negativas, exteriores e repressivas do poder. Devemos percebê-la como práticas “concebidas ao mesmo tempo como modo de agir e de pensar que dão a chave da inteligibilidade para a constituição correlativa do sujeito e do objeto” (FOUCALT, 2004, p. 238). Talvez isto possa ser feito arrancando a emancipação de suas idéias agregadas, até 
modificá-la conforme o sentido da literalidade de sua etimologia, como uma resistência e recusa, de simplesmente não sermos guiados pela mão de alguém. Portanto, emancipar-se para não sermos mais conduzidos pela diversidade de poderes a que estamos relacionados. Emancipação como prática de liberdade, busca de um propósito, estilo de vida ou direção própria, o que a coloca muito próxima da atitude foucauldiano de crítica.

Nas palavras de Vera Portocarrero (2006, p. 193) sobre a crítica, “esta atitude consiste na capacidade e na coragem de elaborar sua própria subjetividade, afastada da 'verdade' e do ‘sujeito-identidade’ e do poder normalizador da lei e das ciências do homem”. Portanto uma emancipação-crítica que não se detenha na conscientização dos próprios limites. Ao contrário, uma emancipação-crítica que seja um transbordamento dos limites a que estamos submetidos como sujeitos em nome da verdade.

\section{Referências}

ABBAGNANO, Nicola. Dicionário de filosofia. São Paulo: M. Fontes, 2003.

CASTELLO, L. A., MÁRSICO, C.T. Oculto nas palavras. Dicionário Etimológico de termos usuais na práxis docente. Belo Horizonte: Autêntica, 2007.

. Dits et écrits.T. IV. Paris: Gallimard, 1994.

. Crítica y Aufklãrung [“Qu’est-ce que la Critique?”]. In: Revista de Filosofía -

Universidad de Los Andes. Mérida, n. 8, p. 5-30, 1995.

Ditos \& Escritos IV (Estratégia poder-saber). Rio de Janeiro: Forense Universitária. 2003.

. Ditos \& Escritos V ( Ética, sexualidade, política). Rio de Janeiro: Forense Universitária. 2004.

. Ditos \& Escritos II (Arqueologia das Ciências e História dos Sistemas de

Pensamento). Rio de Janeiro : Forense Universitária. 2005a.

. Microfísica do Poder. Rio de Janeiro: Graal. 2005b.

. A ordem do discurso. São Paulo: Loyola. 2006a.

. Ditos \& Escritos III (Estética: Literatura e Pintura, Música e Cinema). Rio de Janeiro : Forense Universitária. 2006b.

. Historia de la locura em la época clasica. Vol. I. E-book disponível em:

<http://www.uruguaypiensa.org.uy/noticia_160_1.html>. Acesso em: 31/01/2008a.

. Historia de la locura em la época clasica. VoI. II. E-book disponível em m:

<http://www.uruguaypiensa.org.uy/noticia_160_1.html>. Acesso em: 31/01/2008b. PORTOCARRERO, Vera. Reabilitação da concepção de Filosofia como ascese no 
pensamento tardio de Foucault. In: KOHAN, Walter Omar e GONDRA, José (Orgs.).

Foucault 80 anos. Belo Horizonte: Autêntica, 2006.

REVEL, Judit. Michel Foucault: conceitos essenciais. São Carlos: Claraluz, 2005.

SARDINHA, Diogo. Reinventando o sujeito e a crítica. Os Antigos, Kant e Boudelaire. In:

KOHAN, Walter Omar e GONDRA, José (Orgs.). Foucault 80 anos. Belo Horizonte:

Autêntica, 2006.

\begin{abstract}
${ }^{\text {i }}$ Artigo originalmente apresentado em setembro de 2009 no II Encontro Nacional do Grupo de Trabalho Filosofar e Ensinar a Filosofar da Associação Nacional de Pós-Graduação em Filosofia (ANPOF), realizado na Universidade Gama Filho, no Rio de Janeiro.

${ }^{\text {ii }}$ Mestre em educação pela Universidade do Estado do Rio de Janeiro; Professor da Faculdade Salesiana de Vitória. Email: arpicoli@hotmail.com

iii “'Criticar' originou-se a partir do grego kritikós, 'crítico', adjetivo derivado do verbo krino, que se referia originariamente a uma atividade concreta como a de filtrar -farinha, por exemplo-, cujo correspondente em português é 'peneirar'. A partir daí tomou o sentido de 'escolher' dada a atividade mental que a ação implicava, e depois o sentido mais abstrato ainda de 'decidir’, como se encontra no âmbito jurídico, onde o juiz é denominado krités, isto é, o agente que aplica um 'critério' de avaliação de acordo com determinadas pautas e decide sobre um assunto. Observe-se a gênese mais concreta de krités diante de seu equivalente latino iudex, 'juiz', a partir de ius [direito]. A atividade de crítica implica, pois, a análise e a avaliação e não tem, por si mesma o sentido negativo que adquire nos registros coloquiais onde se pressupõe que a avaliação seja negativa” (CASTELLO \& MÁRSICO, 2007, p. 125).

iv iv [...] la crítica es el movimiento por medio del cual el sujeto se arroga el derecho de interrogar a la verdad sobre sus efectos de poder y al poder sobre sus discursos de verdad. En otras palabras, la crítica será el arte de la in-servidumbre voluntaria, el arte de la indocilidad reflexiva. La crítica tendría esencialmente por función la des-sujeción em el juego de lo que pudiéramos llamar la "política de la verdad".

v Entretanto para Diogo Sardinha, "a consideração dos limites por parte de Kant não se reduz de modo algum ao respeito que eles nos merecem, mas implica ao contrário todo um jogo complexo da sua possível transformação" (SARDINHA, 2006, p. 250). E mais: "Foucault, talvez sem intenção e em todo o caso fazendo-nos pensar o contrário, relança uma crítica permanente dos limites que era já a de Kant e da qual a reflexão estética deste último oferece um exemplo incontestável (SARDINHA, 2006, p. 250).

${ }^{v i}$ Muito tempo depois de As Palavras e as Coisas, Foucault deixará de "pensar o 'exterior' como uma passagem ao limite ou como uma pura exterioridade, e que ele lhe dará um lugar no seio mesmo da ordem do discurso: a oposição não será, portanto mais entre o de dentro e o de fora, entre o reino do sujeito e o murmúrio anônimo, mas entre a linguagem objetivada e a palavra de resistência, entre o sujeito e a subjetividade, isto é, aquilo que Deleuze chamará 'a dobra”" (REVEL, 2005, p. 51). Na entrevista de 1976 com P. Werner, “L'extension sociale de la norme” , publicada sob número 173 em Dits et Écrts, vol. 3, Foucault diz nos diz que estamos sempre no interior, a margem é um mito e a fala do exterior é um sonho que não cessamos de repetir: "La marge est un mythe. La parole du dehors est un rêve qu'on ne cesse de reconduire".

vii Os latinos traduziram a téchne grega por ars, mas o sentido de arte era muito mais abrangente do que o que se entende hoje em dia, e indicava "em seu significado mais geral, todo conjunto de regras capazes de dirigir uma atividade humana qualquer” (ABBAGNANO, 2003, 81).

viii Frente y como contraparte de las artes de gobernar, o más bien como compañera y adversaria a la vez, como manera de dudar de ellas, de recusarlas, de limitarlas, de encontrarles una justa medida, de transformarlas, de buscar un escape de esas formas de gobernar o, en todo caso, un desplazamiento a título de reticência esencial, pero también y por ello mismo como línea de desarrollo de las artes de gobernar, habría habido algo que nació en Europa en ese momento, una suerte de forma cultural general, actitud moral y política a la vez, manera de pensar, etc. que simplemente llamaría el arte de no ser gobernado o, incluso, el arte de no ser gobernado así y a este precio. Propondría entonces, como primera definición de la crítica esta caracterización general: el arte de no ser gobernado de una cierta manera.

ix [...] formulations théoriques, comme celles de la philosophie ou de la science; elle peut et doit être analysée dans toutes lês manières de dire, de faire, de se conduire où l'individu se manifeste et agit comme sujet de connaissance, comme sujet éthique ou juridique, comme sujet conscient de soi et des autres. En ce sens, la pensée est considérée comme la forme même de l'action, comme l'action en tant qu'elle implique le jeu du vrai et du faux, l'acceptation ou le refus de la règle, le rapport à soi-même et aux autres. L'étude des formes d'expérience pourra donc se faire à partir d'une analyse des «pratiques» discursives ou non, si on désigne par là les différents systèmes d'action en tant qu'ils sont habités par la pensée ainsi entendue.
\end{abstract}

